\title{
The Marital Status of Aged Persons in Norway
}

\author{
STÅLE DYRVIK
}

\section{Introduction}

During 1984, approximately 20000 men and 23000 women will reach the age of 67 , which is the retirement age. These numbers will increase notably in the next decade, and, after a short interval, new sustained growth will commence early in the next century. This is one expression of the well-known process of aging which is going on in all industrialized countries.

Until recently public opinion has been so preoccupied with the size of the retired population that other aspects of aging have been neglected. A scarcely explored field, but an important one, is the distribution of the elderly on families and households. The fact that two aged persons live together and not separately will have considerable impact upon their economy, consumption, demand for lodging and, particularly, their need of care and medical treatment. From the public point of view, many single persons will accentuate the economic, medical and social costs of aging.

To build a model for the projection of family status is a very demanding task. Therefore we chose to approach the subject through nuptiality and marital status. It implies that we identify »single» and »not married» (i.e. unmarried, divorced, widowed), which is a rough simplification of reality. Both cohabitation without marriage, collective residential patterns and different forms of cooperation and assistance within the kin group and the neighbourhood may break the isolation inherent in the word »single». We still assume that the marital status of married is the only quantifiable and unequivocal opposite to single - at least in the present state of research.

Even if the investigation becomes much easier when family status is replaced by marital status, only one study of this kind exists in the Norwegian scientific literature: Brunborg, Mønnesland and Selmer (1981). It contains a projection of the population by marital status from 1979 to 2025 . Three alternatives are used: a low one, which prolongs the declining nuptiality of the 1970s until 1987 and keeps it constant thereafter; a constant one based on the 1979 observations; and a high one which inverses the low alternative. The results deserve sincere reflection. Even according to the constant alternative, the percentage of married among the elderly will diminish, and considerably so according to the low alternative which now in 1984 seems most likely (Table 1).

There is no doubt that the same large birth cohorts who will expand the higher age groups early in the next century, are now undergoing a reversal in nuptiality which augurs a crucial shift from married to single marital status. The change of trend is so violent that the pioneer study of Brunborg. Mønnesland and Selmer ought to be updated soon.

The first goal of the present investigation is to construct a manageable model which makes it possible, on the basis of nuptiality and mortality observations in a single year or a short succession of years, to calculate the corresponding structure by marital status throughout the age groups from 15 upwards. Of course, the results will have poor projective value. The aim is rather to disclose the consequences of actual demographic behavior, much as when we calculate the net reproduction ratio of a given year.

A model of this kind might be useful in several ways. Perhaps it will show that the field of nuptiality still deserves the interest of Scandinavian demographers, 
T a b le 1. Percentage married among 67 years old Norwegian men and women

\begin{tabular}{lccc}
\hline \multirow{2}{*}{ Sex } & Obs. & \multicolumn{2}{c}{ Projected till 2025: } \\
& 1979 & Alt. constant & Alt. low \\
\hline Men & 78 & 65 & 57 \\
Women & 56 & 49 & 43 \\
\hline
\end{tabular}

Source: Brundborg et al. (1981), Table 5, pp. 54 and 58

who have started to abandon it under the impression of the progress of informal cohabitation. It might serve as a warning against the tendency to subdivide the study of nuptiality. To investigate first marriages, divorces and remarriages in isolation and in limited age spans leads to a loss of overview. By connecting the different components, not only does the global trend appear, but it becomes feasible to see how it is influenced by changes in each individual component. Such an evaluation is the second aim of this study.

\section{Declining percentages of married among the elderly}

The model is presented in the Appendix (see p. 95 and 96). It does not satisfy high demands on precision. The results should therefore be considered only as indicative.

Full calculations for the years $1865,1950,1960,1970$ and 1982 have been made. The data on mortality are taken from several calendar years, usually the preceding five-year period. The nuptiality data used in the 1865 calculation pertain to the decade 1861-70. All other data concern only the year in question.

We begin by comparing the calculations for 1960 and 1982. They are presented extensively in Table 2 (see p. 90), and in condensed form in Figure 1 (see p. 91). The figure consists of pairs of columns where the left column shows the observed marital structure of the actual year while the right on indicates the message of the model, namely the distribution inherent in the demographic behavior that year.

In 1960 the observed distribution has fewer married and more single persons than the distribution that would result from the actual conditions of mortality and nuptiality. This is not surprising: The elderly in 1960 had created and dissolved families between the world wars, while the young people belong to the marriage boom of the post-war period. In 1982 this picture is completely reversed. We register far greater percentages of married among the mature than might be expected from the new behavior of the young ones.

How do these results of the transversal model correspond with the projection of Brunborg et al.? If we retain the 1982 pattern and interpolate to find the proportion married at the age of 67 , we get 61 percent for men and 48 percent for women. These quantities are rather nicely enclosed by the alternatives constant (constant from 1979) and low (decline until 1987, then constant) in Brunborgs study - see Table 1 . This might be taken as an indication of the validity of the model.

\section{Why more single persons}

While the demographic pattern of 1960 "announced" 62 percent married among men of age 80 , the corresponding calculation for 1982 showed only 50 
$\mathrm{T} \mathrm{a} \mathrm{b} \mathrm{l} \mathrm{e} \mathrm{2.} \mathrm{Marital} \mathrm{status} \mathrm{of} \mathrm{men} \mathrm{and} \mathrm{women} \mathrm{according} \mathrm{to} \mathrm{the} \mathrm{patterns} \mathrm{of}$ nuptiality and mortality in Norway in 1960 and 1982. Percent.

\begin{tabular}{|c|c|c|c|c|c|c|c|c|c|c|}
\hline $\begin{array}{l}1960 \\
\mathrm{Ag}\end{array}$ & $\begin{array}{c}\text { Men } \\
\text { U }\end{array}$ & M & D & W & Sum & $\begin{array}{c}\text { Women } \\
\mathrm{U}\end{array}$ & M & D & W & Sum \\
\hline 15 & 100.0 & & & & 100.0 & 100.0 & & & & 100.0 \\
\hline 20 & 97.4 & 2.6 & 0.0 & 0.0 & 100.0 & 84.6 & 15.4 & 0.0 & 0.0 & 100.0 \\
\hline 25 & 59.3 & 40.6 & 0.1 & 0.0 & 100.0 & 24.6 & 74.9 & 0.5 & 0.1 & 100.1 \\
\hline 30 & 23.3 & 75.4 & 1.2 & 0.1 & 100.0 & 7.3 & 90.1 & 2.0 & 0.6 & 100.0 \\
\hline 35 & 13.1 & 84.4 & 2.2 & 0.3 & 100.0 & 4.1 & 92.2 & 2.5 & 1.1 & 99.9 \\
\hline 40 & 9.6 & 87.2 & 2.6 & 0.5 & 99.9 & 3.2 & 91.9 & 3.1 & 1.8 & 100.0 \\
\hline 45 & 8.0 & 88.4 & 2.7 & 0.9 & 100.0 & 2.8 & 90.4 & 3.7 & 3.1 & 100.0 \\
\hline 50 & 7.4 & 88.0 & 3.2 & 1.4 & 100.0 & 2.6 & 88.1 & 4.1 & 5.2 & 100.0 \\
\hline 55 & 7.0 & 87.3 & 3.3 & 2.4 & 100.0 & 2.5 & 84.2 & 4.5 & 8.8 & 100.0 \\
\hline 60 & 6.8 & 85.9 & 3.4 & 3.9 & 100.0 & 2.4 & 78.3 & 4.8 & 14.4 & 99.9 \\
\hline 65 & 6.7 & 83.1 & 3.5 & 6.6 & 99.9 & 2.4 & 70.1 & 5.0 & 22.5 & 100.0 \\
\hline 70 & 6.6 & 78.8 & 3.7 & 10.9 & 100.0 & 2.4 & 59.3 & 5.1 & 33.2 & 100.0 \\
\hline 75 & 6.6 & 71.9 & 3.6 & 18.0 & 100.1 & 2.4 & 46.4 & 5.1 & 46.1 & 100.0 \\
\hline 80 & 6.6 & 62.1 & 3.7 & 27.6 & 100.0 & 2.4 & 33.2 & 5.1 & 59.3 & 100.0 \\
\hline 1982 & Men & & & & & Women & & & & \\
\hline Age & $\mathrm{U}$ & M & D & W & Sum & $\mathrm{U}$ & M & D & W & Sum \\
\hline 15 & 100.0 & & & & 100.0 & 100.0 & & & & 100.0 \\
\hline 20 & 98.6 & 1.4 & 0.0 & 0.0 & 100.0 & 91.8 & 8.2 & 0.0 & 0.0 & 100.0 \\
\hline 25 & 74.2 & 25.7 & 0.1 & 0.0 & 100.0 & 53.8 & 45.7 & 0.5 & 0.0 & 100.0 \\
\hline 30 & 44.4 & 53.7 & 1.8 & 0.0 & 99.9 & 30.7 & 65.5 & 3.5 & 0.3 & 100.0 \\
\hline 35 & 31.9 & 63.5 & 4.5 & 0.1 & 100.0 & 22.6 & 70.4 & 6.4 & 0.7 & 100.1 \\
\hline 40 & 27.3 & 65.6 & 6.8 & 0.3 & 100.0 & 19.7 & 70.2 & 8.8 & 1.3 & 100.0 \\
\hline 45 & 25.3 & 65.4 & 8.7 & 0.6 & 100.0 & 18.5 & 68.3 & 10.8 & 2.4 & 100.0 \\
\hline 50 & 24.4 & 64.6 & 10.1 & 1.0 & 100.1 & 17.8 & 66.1 & 11.7 & 4.3 & 99.9 \\
\hline 55 & 23.9 & 64.0 & 10.4 & 1.6 & 99.9 & 17.4 & 63.4 & 12.0 & 7.2 & 100.0 \\
\hline 60 & 23.7 & 63.2 & 10.4 & 2.7 & 100.0 & 17.3 & 58.6 & 12.3 & 11.8 & 100.0 \\
\hline 65 & 23.5 & 61.8 & 10.3 & 4.3 & 99.9 & 17.2 & 51.9 & 12.4 & 18.5 & 100.0 \\
\hline 70 & 23.4 & 59.4 & 10.3 & 6.9 & 100.0 & 17.1 & 43.2 & 12.5 & 27.2 & 100.0 \\
\hline 75 & 23.3 & 55.6 & 10.3 & 10.8 & 100.0 & 17.1 & 32.6 & 12.5 & 37.8 & 100.0 \\
\hline 80 & 23.3 & 50.2 & 10.2 & 16.2 & 99.9 & 17.1 & 22.3 & 12.5 & 48.1 & 100.0 \\
\hline
\end{tabular}

percent. For women, there was a decline from 33 to 22 percent. What had happened between 1960 and 1982 that had effects of the kind? Our model is already in its conception so crude that we shall allow the simplification of quite simply moving the 1982 components one by one back into the 1960 context and reading the relative impact on the original proportion of married. This is shown in Table 3.

By far the most important contribution to the falling percentages of married among the elderly is due to the decline of first marriages, the basic event in the creation of families. The growing tendency to divorce follows as a distinct number two. The patterns of remarriage has only small significance: Remarriage among divorced is weakened, while remarriage among widowed persons remain stable.

The joker of this game is mortality: It is the only component to be found on the positive side, the only to be clearly different for men and women, and the only to give varying effects according to age. Generally, the development of mortality has contributed to increase the proportions of married among men, particularly in the higher age groups. For women the development has been quite opposite. 
$\mathrm{T}$ a b l e 3. Effects on the proportion married of changes in single components 1960-1982. Percent.

\begin{tabular}{lrrrrrrr}
\hline & & \multicolumn{5}{c}{ Effects on the 1960 population } \\
& & Men & & \multicolumn{3}{c}{ Women } \\
1982 Component & 50 & 65 & 80 & 50 & 65 & 80 \\
\hline First marriages & & & -18 & -18 & -15 & -15 & -14 \\
Dissolutions by divorce & -7 & -6 & -5 & -8 & -8 & -8 \\
Remarriages of divorced & -1 & -2 & -2 & -1 & -1 & -2 \\
Dissolutions by death of spouse & 0 & 2 & 10 & 0 & -2 & -11 \\
Remarriages of widowed & 0 & -1 & -1 & -1 & -1 & -1 \\
\hline
\end{tabular}

F i g u r e 1: Distribution by marital status of men and women in Norway in 1960 and 1982: Observed (A) and latent in the patterns of nuptiality and mortality (B) by age 65 and 80 . Percentages.
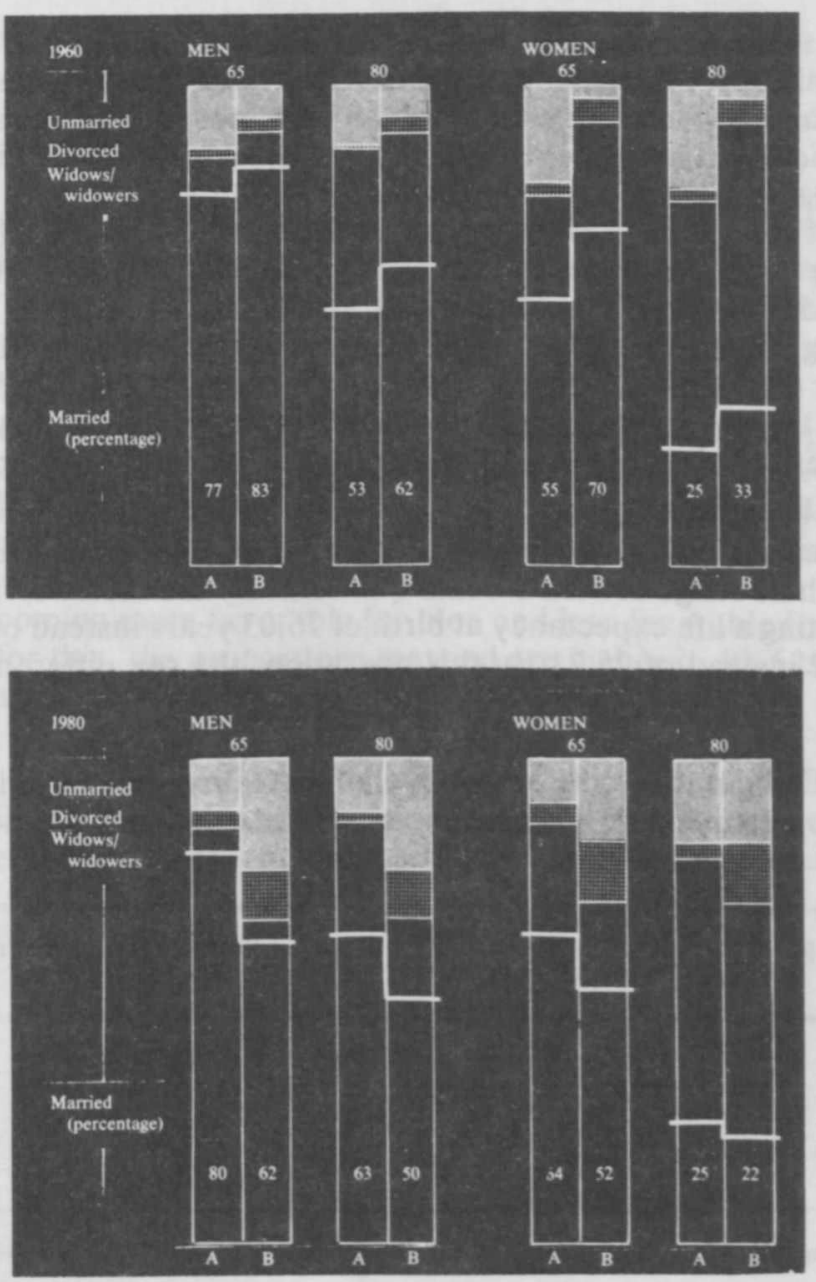


\section{The mortality component}

It is a common sense conclusion that when the overall mortality is declining, the dissolution of marriages by death of a spouse will be transferred to higher age. This in turn - all other things being equal - will lead to higher proportions of married persons in the population. In the post-war period, life expectancy has developed as demonstrated in Table 4. Mortality has fallen, but notably faster for women than for men. Men above 50 even show higher risks of death. How can such a trend favor the men, as we have just seen?

$\mathrm{T}$ a b l e 4. Life expectancy in Norway in the post-war period

\begin{tabular}{|c|c|c|c|c|c|c|}
\hline \multirow[b]{2}{*}{ Period } & \multicolumn{3}{|c|}{ Life expectancy at birth: } & \multirow[b]{2}{*}{ Men } & \multirow[b]{2}{*}{ Women } & \multirow{2}{*}{$\begin{array}{l}\text { At age } 50 \text { : } \\
\text { Difference }\end{array}$} \\
\hline & Men & Women & Difference & & & \\
\hline $1946-50$ & 69.25 & 72.65 & 3.40 & 26.43 & 27.95 & 1.52 \\
\hline $1956-60$ & 71.32 & 75.57 & 4.25 & 26.21 & 28.84 & 2.63 \\
\hline $1966-70$ & 71.09 & 76.83 & 5.74 & 25.32 & 29.47 & 4.15 \\
\hline $1979-80$ & 72.25 & 79.00 & 6.75 & 25.71 & 30.98 & 5.27 \\
\hline
\end{tabular}

The mechanism is, of course, that the transition from state "alive and married» to state "alive and widowed» is determined by the mortality of the spouse, not of one's own. Widening sex gaps in mortality favor marital status married among the sex dropping behind.

A couple of examples of these effects will be presented. In table 5 we have used model life tables to obtain an idea of the combined effects of mortality level and mortality differences. The experiment can be summed up in the following way: By falling mortality the proportions of married increase. But if mortality ameliorates for one sex only, this sex will experience diminishing proportions of married, while the proportions for the sex with unchanged mortality will increase markedly. To establish exact measures of these effects is not the purpose here.

The principle might also be illustrated by means of the available Norwegian data. The factual sex differences in 1979-80 appear in Table 4. By tentatively reducing the whole range of men's death quotients by the factor 0.75 , a new table is made presenting a life expectancy at birth of 76.03 years instead of 72.25 , and at age 50 of 28.82 instead of 25.71 . By this operation, the sex difference is reduced

$\mathrm{T}$ a b l e 5. Estimated effects of the level of mortality and mortality differences on proportions married among elderly men and women. Model life tables.

\begin{tabular}{cccc}
\hline $\begin{array}{c}\text { Life expectancy at birth } \\
\text { Men }\end{array}$ & Women & $\begin{array}{c}\text { Percentage married at age } 80 \\
\text { Men }\end{array}$ & $\begin{array}{c}\text { Women } \\
\text { (31.80 }\end{array}$ \\
61.80 & 61.80 & 27 & 26 \\
72.79 & 65.43 & 32 & 25 \\
72.79 & 72.79 & 34 & 34 \\
& 76.02 & 40 & 33 \\
\hline
\end{tabular}

Source: Ledermann (1969), reseau 100, pp. 94 and 100. 
$\mathrm{T}$ a b l e 6. Estimated effects of lower mortality for men on the percentages of married among elderly men and women

\begin{tabular}{lccccccc}
\hline & \multicolumn{3}{c}{ Men } & \multicolumn{3}{c}{ Women } \\
& 50 & 65 & 80 & 50 & 65 & 80 \\
\hline Observed mortality $1979-80$ & 65 & 62 & 50 & 66 & 52 & 22 \\
Men changed to e $0=76.03$ & 64 & 61 & 44 & 68 & 59 & 37 \\
\hline
\end{tabular}

approximately to the level of the early post-war years. What will be the impact of this manipulation on the distribution by marital status of 1982? Table 6 reveals only modest changes at 50 years, but by 80 they have considerable momentum: The proportions of married men fall from 50 to 44 percent, and increase for women from 22 to 37 percent.

These few examples suggest the importance of supervising the role of sex-differential mortality in the study of family status among the elderly.

\section{A historical comparison}

The discussion of the mortality component conveniently serve as a point of departure for a comment on the long-run development of the family's processes of dissolution and renewal. The situation in 1982 will be compared to that of 1865 , for which quite adequate data are to be found. A century ago, divorces and remarriages of divorced persons were sufficiently rare for us to ignore them. The most spectacular difference to the present time is the much higher mortality. Life expectancy at birth was in 1856-65 47.5 years for men and 50.0 years for women. One therefore expects to find a much harder wear on the stock of marriages by death, counterbalanced by very frequent remarriages among widowers and widows. But is this true?

The first surprise arises when the model is used to calculate proportions of married in the two years. It appears from Table 7 that the ancient population comes out with relatively many married persons, in spite of the high mortality. Admittedly, there are considerable differences between the sexes in 1865 , due to recent emigration and growing numerical imbalance. Gradually, the marriage market was becoming more favorable for men and less favorable for women. But even allowing for this, the proportions married are higher in 1865 both at ages 50 and 65 , and only slightly lower at age 80 .

$\mathrm{T}$ a b l e 7. Proportions married among the elderly, estimated from the demographic patterns of the years 1865 and 1982

\begin{tabular}{lllll}
\hline & & & & Age \\
& & 50 & 65 & 80 \\
\hline \multirow{2}{*}{1865} & Men & 83 & 74 & 46 \\
& Women & 73 & 53 & 22 \\
& Men & 65 & 62 & 50 \\
& Women & 66 & 52 & 22 \\
\hline
\end{tabular}


A first step towards an explanation must imply an evaluation of the mortality factor. The modest life expectancy is rather deceptive because it is so greatly influenced by the infant mortality, while we are concerned with the adult mortality only. The life expectancy at the age of 15 was 46.9 years for men and 49.1 years for women in the $1860 \mathrm{~s}$, compared to 58.3 and 64.8 in $1979-80$. At age 50 the expectancy was 22.0 years for men and 23.4 years for women, and now the difference to the present level of 25.7 and 31.0 (see Table 4) is even less striking. Therefore, the mortality factor might not be the only one of interest.

The next step of the analysis is identical to the one demonstrated earlier (see pp. 89-91). Moving the 1982 components one by one into the 1865 context and reading the effect upon the phenomenon under scrutiny (Table 8). As was to be expected, the low 1982 mortality leads to a strong increase in the percentages of married among effect must have been more than offset by other negative components. It is rather surprising, however, to ascertain that remarriage of widowed persons is not among them: It has not declined during the last century. Widowers and widows today make new couples as they have always done. Remarriage has merely become rare because of the decline of mortality and fewer cases of widowhood. It also goes without saying that remarriage is a mechanism of repair that can never turn into a negative component in a strict sense. The counterbalance to the falling mortality must therefore be sought elsewhere. Table 8 tells that the decline in first time nuptiality and the appearance of divorce (which is in turn partly checked by remarriages) are of about equal importance. To sum up: What was gained by lower mortality and fewer marriges dissolved by death was given away as decline in first marriages and net loss by divorce.

T a b l e 8. Relative impact on proportions married of changes in single components $1865-1982$

\begin{tabular}{lrrrrrr}
\hline & \multicolumn{7}{c}{ Effects on the 1865 population } \\
& Men & & & Women \\
& 50 & 65 & 80 & 50 & 65 & 80 \\
\hline First marriages & & & & & & \\
& -16 & -16 & -16 & -4 & -5 & -5 \\
Divorces and remarriages & -12 & -12 & -12 & -12 & -13 & -13 \\
Dissolutions by death of spouse & 7 & 16 & 49 & 11 & 22 & 28 \\
Remarriages of widowed & -3 & -6 & -5 & -3 & -3 & -3 \\
\hline
\end{tabular}

\section{Conclusion}

This small study has shown that it does not present difficulties to create a simple transversal model for the marital structure of a population, that is, a model which on the basis of observed nuptiality and mortality in a given short span of time can suggest the marital structure the population is heading towards.

The projective value of such calculations is modest. The structure by marital status is built up in a population over decades. It is unprobable that the demographic behavior of one or a few calendar years will remain stable long enough to put its stamp on the global structure. The value is rather that the model catches the sum of several indistinct components, and even makes it possible to evaluate the contribution of each component.

The main result is simple: between 1960 and 1982 the total marriage pattern has experienced a profound change. The trend no longer indicated increase but drastic decline in the proportions married in the population (Table 2, Figure 1). All age groups are influenced. 
The components of this change could mentally be arranged along an age axis: first marriages and divorces are most effective in the lower age groups, while remarriages among divorced, dissolutions of marriages by death and remarriages of widowed persons become more important as age increases. As we are mainly concerned with the marital status of the older part of the population, we might expect remarriage and mortality to be of main interest.

This is only partly confirmed by our findings. Whatever age groups we investigate, the decline in first marriages is the most important single change. The first marriage is the fundamental event of which most of the others are directly or indirectly dependent. Dissolution of marriage by divorce has also contributed substantially, even if its importance might have been exaggerated in public opinion. If we turn to the higher age groups, we find that the nuptiality components lose effect here. The marital composition achieved by age 50 or 60 is hard to change later on. The stage is left almost entirely to the »external» mortality component, i.e. dissolution of marriage by death of spouse.

We have not only got a confirmation of the self-evident, that the proportions married in the higher age groups grow when the life expectancy grows. It has also been possible to state that an accentuation of sex-differential mortality has substantial effects on the marital status of the elderly: smaller proportions of married of the favored sex, and greater for the other one.

The family situation of aged persons will no doubt become an important issue in social policy in the next decades. Growing proportions of singles combined with greater social isolation might aggravate the problems of aging. To be able to watch the trends, transversal analyses of the kind presented in this paper are inadequate. The work on projections of marital status should continue. We need to know much more abour cohabitation without marriage. And the core of the problem is still the registration and projection of families and households.

\section{Appendix: the model}

The components of the model are first marriage, dissolution of marriage by divorce, dissolution of marriage by death (i.e. the mortality of the two sexes), remarriage among divorced, and remarriage among widowed persons.

The model does not conform to high demands of precision: it uses five-year age groups. The available printed statistics do not supply satisfactory information on marriage and divorce for age groups above 70 . Calculations are made for the two sexes separately, even when mortality reveals modifications affecting offer and demand on the marriage market.

For each of the components rates are calculated for five-year age groups between 15 and 80 years. The rates are converted to probabilities of transition or quotients according to the formula

$$
q=\frac{2 \mathrm{ar}}{2+\mathrm{ar}}
$$

where $\mathrm{q}$ is the quotient, $\mathrm{r}$ the rate and a the age span (here 5). The sixth set of quotients, concerning dissolution of marriage by death of spouse, is found as the product of one's own probability of survival and the death risk of the opposite sex. Men are considered 3 years older than their spouses.

The calculations, performed for each sex separately, starts with 10000015 years olds. These variables are used: 
Populations Probabilities of transition

$$
\begin{array}{ll}
\mathrm{U}=\text { unmarried } & \mathrm{q}=\text { death } \\
\mathrm{M}=\text { married } & \mathrm{w}=\text { loss of spouse } \\
\mathrm{D}=\text { divorced } & \mathrm{f}=\text { first marriage } \\
\mathrm{W}=\text { widowed } & \mathrm{d}=\text { divorce } \\
& \mathrm{g}=\text { remarriage of divorced } \\
& \mathrm{h}=\text { remarriage of widowed }
\end{array}
$$

Using the numbers 1 and 2 to indicate one age step and the following, the equations become:

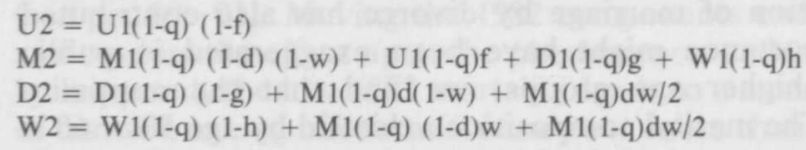

\section{References}

Brunborg, H.; Mønnesland, J. and Selmer, R. (1981). Framskriving av folkemengden etter ekteskapelig status 1979-2025. Rapporter 81/12. Statistisk Sentralbyrå, Oslo.

Ledermann, S. (1969). Nouvelles tables types de mortalite. Paris. 